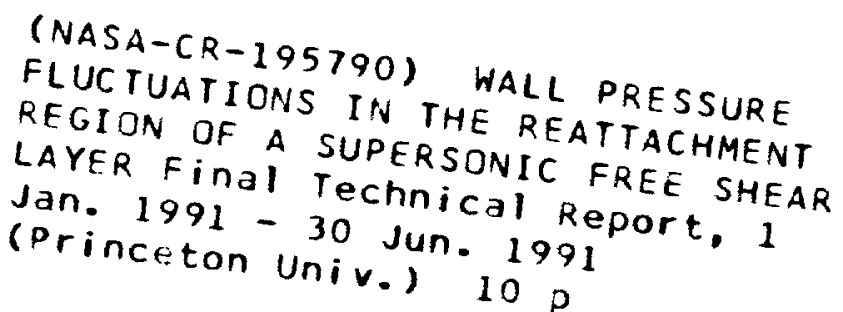

$63 / 02 \quad 0004482$ 
Final Technical Report

NASA Langley Grant NAG-1-1072

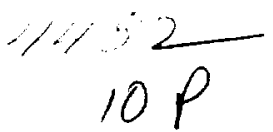

Wall Pressure Fluctuations in the Reattachment Region of a Supersonic Free Shear Layer

by

Professor Alexander J. Smits

Department of Mechanical and Aerospace Engineering

Princeton University

Princeton, NJ 08544

Attention: Dr. William E. Zorumski

Chief Scientist

Fluid Mechanics and Acoustics Division

Mail Stop 462

NASA Langley Research Center

Hampton, VA 23665-5225

April 14, 1994

\begin{abstract}
This report is the final technical report for NASA Research Grant NAG-1-1072, under the administration of Dr. William E. Zorumski, covering the period 1/1/91 to $6 / 30 / 91$.
\end{abstract}

\title{
Description of Project
}

The primary aim of this research program was to investigate the mechanisms which cause the unsteady wall-pressure fluctuations in shock wave turbulent shear layer interactions. The secondary aim was to find means to reduce the magnitude of the fluctuating pressure loads by controlling the unsteady shock motion. The particular flow under study is the unsteady shock wave interaction formed in the reattachment zone of a separated supersonic flow. Similar flows are encountered in many practical situations, and they are associated with high levels of fluctuating wall pressure.

The free shear layer is formed by the flow over a backward facing step, using an existing model, with the base pressure on the step adjusted so that there is no pressure discontinuity at the lip (see Figures 1 and 2). The shear layer therefore develops in a zero pressure gradient. The primary advantage of this flow configuration is that the reattachment process can be studied in the absence of a 
separation shock. The mean flow data, and some preliminary hot-wire measurements of the mass-flux fluctuations were made by Baca[1] and Settles, Baca, Williams and Bogdonoff[2], who showed that the shear layer became selfthe observed Mach number difference lip, and that it grew at a rate typical of rate). The turbulence measurementence (about $1 / 3$ rd the incompressible growth Bogdonoff $[3]$ under NASA Headquarters supportended by Hayakawa, Smits and

\section{Progress}

In the early work supported by the present grant[4], wall pressure fluctuations were measured in the reattachment region of the supersonic free shear layer using an array of flush-mounted, miniature, high-frequency pressure transducers, and some preliminary images of the instantaneous shock structure were obtained using Rayleigh scattering to visualize the instantaneous density field.

Contrary to previous observations of this flow, the reattachment region was found to be highly unsteady, and the pressure fluctuations were found to be significant. The most remarkable feature observed in the pressure fluctuation data was the dramatic increase in large amplitude pressure fluctuation near the reattachment point, which reached a maximum of about $11 \%$ of the local mean pressure. The pressure fluctuations fell off gradually in the redeveloping boundary layer downstream. The results also showed that the flow in the ramp is divided into two regions, a reattachment and a redevelopment region. Near reattachment, the pressure fluctuations greatly increase, and large scale structures breakdown into smaller scales. Downstream of reattachment, the fluctuating
properties gradually decline and the boundary layer recovers its structure.

The preliminary visualization study using the Rayleigh technique also yielded some interesting results. The images taken in a streamwise plane near reattachment indicated an apparent shock splitting, which seemed to extend considerably upstream of the mean reattachment point. No two images were
alike, showing how the strong pressure fluctuations observed on the ramp
coupled with a high degree of unsteady shock motion. coupled with a high degree of unsteady shock motion.

When the plane of the light sheet was oriented parallel to the freestream direction, the image gave an instantaneous plan view of the large scale organization of the shear layer. Some plan views gave a strong indication that a spanwise, and a streamwise structure exists, in accordance with previous subsonic observations at low Reynolds number. Near the ramp the streamwise organization was particularly evident, suggesting the presence of Taylor-Gortler-like vortices near reattachment, as has been speculated in the past (Selig et al.[7]). When the plane of light was tilted so that it made an angle of about $20^{\circ}$ with the plane of the ramp, a most remarkable spanwise wrinkling of the reattachment shock was made
visible. Hence, the instantaneous shock structure in the reattachment zone was
found to be very complex: found to be very complex: there is streamwise shock splitting, and spanwise shock wrinkling, so that there can exist "cells" enclosed by shock sheets. 
The evidence presented by Shen et al.[4] for the shock unsteadiness and the shock wrinkling prompted two questions. Was it the result of an interaction with the longitudinal structures seen in the incoming shear layer? And can the unsteadiness be controlled by modifying the shear layer structure? Here, we report the first application of control methods in an attempt to change the level of the fluctuating pressure loads. The particular control method used was steady blowing into the recirculation zone near the backward-facing step.

The blowing took place through a $3.2 \mathrm{~mm}(0.125$ ") hole drilled in the floor of the cavity, on the centerline of the model, as close as possible to the vertical face of the backward-facing step. The supply pressure was varied from $1.35 \times 10^{6} \mathrm{~Pa}$ (200psia) to $0.17 \times 10^{6} \mathrm{~Pa}$ (25 psia). The corresponding mass flow rates were $0.0233 \mathrm{Kg} / \mathrm{s}$, and $0.0029 \mathrm{Kg} / \mathrm{s}$, respectively. The flow response was similar for all supply pressures, and the differences observed in the flow response for different blowing rates were only a matter of degree. All results presented here were taken at a blowing supply pressure of $0.68 \times 10^{6} \mathrm{pa}(100 \mathrm{psia})$, and a mass flow rate of $0.0116 \mathrm{Kg} / \mathrm{s}$.

The schlieren flow visualizations shown in Figure 3 were taken using a horizontal knife edge. The exposure time is less that 2 microseconds, during which time the freestream moves less than $1 \mathrm{~mm}$. To make these images possible, the opaque side fences were removed (these are normally used to improve the two-dimensionality of the flow in the reattachment region). In addition, the side edges of the cavity were cut down $15.9 \mathrm{~mm}\left(0.625^{\prime \prime}\right)$ to reveal the lower edge of the free shear layer. It should be noted that the lower black edge in each of the images is still $9.5 \mathrm{~mm}$ ( $\left.0.375^{\prime \prime}\right)$ above the bottom of the cavity. The images were recorded on 0.5 " $\mathrm{S}$ VHS videotape, and grabbed using an Imaging Technology Image Processor controlled by a Silicon Graphics Personal Iris workstation. The greylevels were offset and amplified by a fixed amount to improve the contrast.

In Figure 3, schlieren flow visualizations are shown of the flow separating from the backward-facing step and reattaching on the $20^{\circ}$ ramp. The flow is from left to right. In Figure 3a, there is no blowing and the upper and lower edge of the developing free shear layer are clearly visible. Due to the spanwise integration of density gradients, the edges are almost without feature, although there is some evidence of the turbulent nature of the flow in the appearance of the lower edge. Waves are also visible emanating from the upper edge of the layer. There is an expansion fan centered on the edge of the backward-facing step, indicating that when the fences and cavity sides are removed the pressure inside the cavity no longer exactly matches the freestream value.

The reattaching flow (without blowing) is shown in Figure 3b. The shock is evident as the dark fan-like region seen above the developing boundary layer. The shock appears to be distributed in this manner for two reasons: Because of the absence of the fences the shock will be bowed in the spanwise direction, and there are significant smaller scale spanwise wrinkles on the shock sheet[4]. The highly turbulent region near reattachment is visible despite the integration across the flow. 
In Figure 3c, the separating flow with blowing is shown. The jet is not visible in this image, primarily because of the orientation of the knife edge. Note the shock ahead of the expansion fan: this shock is produced by the jet caused by the blowing, and it is probably highly three-dimensional. One surprising observation is that the shear layer deflects down (note the increased size of the expansion fan), even though mass is being added to the recirculating region, indicating that there is enhanced entrainment in the shear layer. Considerably greater activity is also seen within the recirculating flow.

The most dramatic effect of blowing is seen in the reattachment region (Figure $3 d$ ). The increased thickness of the developing boundary layer is obvious, as is the greatly enhanced distortion of the reattachment shock. Severe curvature and strong displacement of the shock sheet is apparent, indicating a much higher degree of unsteadiness.

Rayleigh images of the same flow are shown in Figure 4. The flow in this case is from right to left. The images do not reproduce well, but the information is interesting because they give quantitative data on the instantaneous density, and they are free of optical integration since they give data in a plane of only $0.2 \mathrm{~mm}$ thickness (the thickness of the laser sheet). Figures 4 a show the reattaching flow without blowing (the picture is oriented as shown in the accompanying sketch), and Figure $4 \mathrm{~b}$ shows the top edge of the separating shear layer, also without blowing (the step is just out of the picture on the right). The convoluted nature of the interface is clear (contrast this with the schlieren image in Figure $3 \mathrm{a}$ ). The weak expansion fan is just visible in the original image, but it does not show up well in the reproduction. In Figures $4 \mathrm{c}$ and $4 \mathrm{~d}$, the same flow is shown, this time with blowing. the weak shock due to the blowing jet is visible as the line demarking a region of increased brightness, but the stronger expansion fan, which should show up as a darker region since the density is decreasing, is not clearly visible. The increased thickness of the shear layer is apparent (all the images in Figure 4 were taken during the same run, and the camera was not moved or adjusted), as is the greatly enhanced turbulent activity near the edge of the shear layer. In the original, compression and expansion waves can be seen emanating from the shear layer, upstream and downstream of the reattachment region, closely coupled with the large-scale motions in the layer. A videotape is available which makes these visualizations extremely graphic.

\section{Conclusions}

This work has shown the strong influence that blowing can have on the development of a separated flow, when the blowing is introduced into the subsonic side of the shear layer. The shear layer grows much more rapidly, there is enhanced turbulent mixing, and the unsteadiness near reattachment is greatly amplified. We believe this was the first time that significant enhancement of mixing in a supersonic free shear layer has been demonstrated. 


\section{List of Publications Acknowledging Grant NAG-1-1072:}

1. Shen, Z.H., Smith D.R. and Smits, A.J., "Wall Pressure Fluctuations in the Reattachment Region of a Supersonic Free Shear Layer", AIAA Paper \#90-1461, AIAA 21st Fluid and Plasmadynamics Conference, Seattle, Washington, June 18-20 1990.

2. Smith, D.R., Poggie, J., Konrad, W. and Smits, A.J., "Visualization of the Structure of Shock Wave Turbulent Boundary Layer Interactions Using Rayleigh Scattering", AIAA Paper \#91-0651, AIAA 29th Aerospace Sciences Meeting, Reno, Nevada, January 1991.

3. Poggie, J., Smits, A.J. and Glezer, A., "The Dynamics and Control of Fluctuating Pressure Loads in the Reattachment region of a Supersonic Free Shear Layer," AIAA Paper \#92-0178, AIAA 30th Aerospace Sciences Meeting, Reno, Nevada, January 1992.

4. Poggie, J. and Smits, A.J., "Control of Pressure Fluctuations in the Reattachment Region of a Supersonic Shear Layer," AIAA Paper \#93-0385, AIAA 30th Aerospace Sciences Meeting, Reno, Nevada, January 1993.

5. Poggie, J. and Smits, A.J., "Mixing Enhancement in a Compressible Turbulent Shear Layer." Paper \#CB7, 44th Meeting of the American Physical Society Division of Fluid Dynamics, Tempe, Arizona, November 24-26, 1991.

6. Shen, Z.-H., Smith, D.R. and Smits, A.J., "Wall Pressure Fluctuations in the Reattachment Region of a Supersonic Free Shear Layer." Experiments in Fluids, Vol. 14, pp. 10-16, 1993.

7. Poggie, J. "Mixing Enhancement in a Compressible Turbulent Shear Layer." Ph.D. Thesis, MAE Department, Princeton University, 1994. Under preparation.

\section{References}

1. Baca, B.K., M.Sc. Dissertation, Princeton Univ. Princeton, N.J., 1981

2. Settles, B.S., Baca, B.K., Williams, D.R. and Bogdonoff, S.M., "A Study of Reattachment of a Free Shear Layer in Compressible Turbulent Flow," AIAA Journal, Vol. 20, pp. 60-67, 1982.

3. Hayakawa, K., Smits, A.J. and Bogdonoff, S.M., "Turbulence Measurements in a Compressible Reattaching Shear Layer," AIAA Joumal, Vol. 22, pp.889-895, 1984.

4. Shen, Z.-H., Smith, D.R. and Smits, A.J., "Wall Pressure Measurements in the Reattachment Region of a Supersonic Free Shear Layer," AIAA Paper 90-1461, 1990. 
5. Smith, M.W., Smits, A.J. and Miles, R.B., Optics Letters, 14: 916-918, 1989.

6. Wegener, P.P. and Stein, G.D., 12th Intern. Symp. on Combustion, 1183-1191, 1968.

7. Selig, M.S., Andreopoulos, J., Muck, K.C., Dussauge, J.-P. and Smits, A.J., "Turbulence Structure in a Shock-Wave/Turbulent Boundary Layer Interaction," AIAA Journal, Vol. 27, pp.862-869, 1989.

8. Smith, D.R., Poggie, J., Konrad, W. and Smits, A.J., "Visualization of the structure of shock wave boundary layer interactions using Rayleigh scattering," AIAA Paper 91-0651, presented at the 29th Aerospace Sciences Meeting, January 7-10, Reno, Nevada. 


\section{FIGURE CAPTIONS}

Figure 1. Geometry for the formation of a free shear layer and its subsequent attachment on a $20^{\circ}$ ramp (from Settles et al.[2]).

Figure 2. Flowfield showing test model and surface static pressure distribution (from Settles et al.[2]).

Figure 3. Schlieren images of the reattaching free shear layer in a streamwise plane. Flow is from left to right. (a) and (b) are without blowing, (c) and (d) are with blowing.

Figure 4. Rayleigh images of the reattaching free shear layer in a streamwise plane. Flow is from right to left. (a) and (b) are without blowing, (c) and (d) are with blowing.

Figure 3. Schlieren images of the reattaching free shear layer in a streamwise plane. Flow is from left to right. (a) and (b) are without blowing, (c) and (d) are
with blowing.

Figure 4. Rayleigh images of the reattaching free shear layer in a streamwise plane. Flow is from right to left. (a) and (b) are without blowing, (c) and (d) are with blowing.

Figure 3. Schlieren images of the reattaching free shear layer in a streamwise plane. Flow is from left to right. (a) and (b) are without blowing, (c) and (d) are with blowing.

Figure 4. Rayleigh images of the reattaching free shear layer in a streamwise plane. Flow is from right to left. (a) and (b) are without blowing, (c) and (d) are with blowing.

Figure 3. Schlieren images of the reattaching free shear layer in a streamwise plane. Flow is from left to right. (a) and (b) are without blowing, (c) and (d) are with blowing.

Figure 4. Rayleigh images of the reattaching free shear layer in a streamwise plane. Flow is from right to left. (a) and (b) are without blowing, (c) and (d) are with blowing.

Figure 3. Schlieren images of the reattaching free shear layer in a streamwise plane. Flow is from left to right. (a) and (b) are without blowing, (c) and (d) are with blowing.

Figure 4. Rayleigh images of the reattaching free shear layer in a streamwise plane. Flow is from right to left. (a) and (b) are without blowing, (c) and (d) are with blowing. 


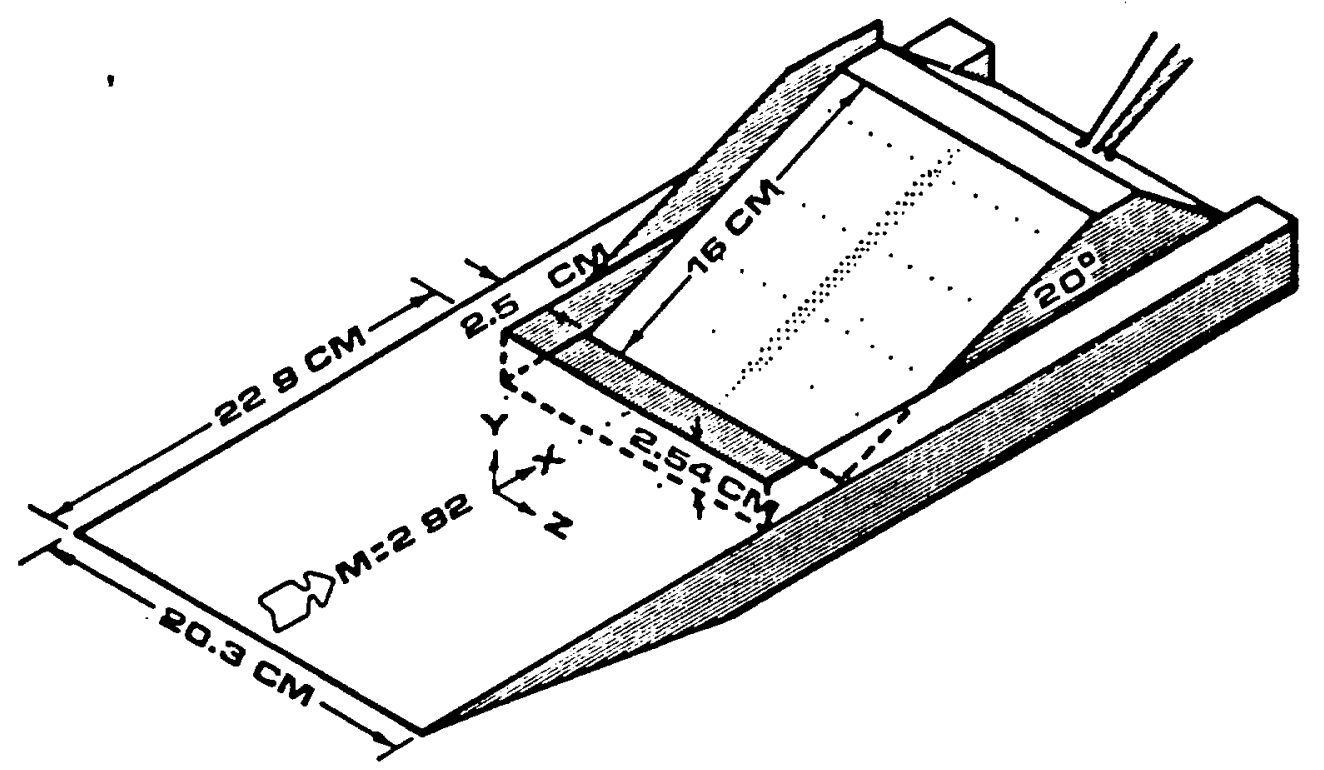

Fig 1. Geometry for the formation of a free shear layer and its subsequent attachment on a $20^{\circ}$ ramp (from Settles et al. ${ }^{2}$ ).

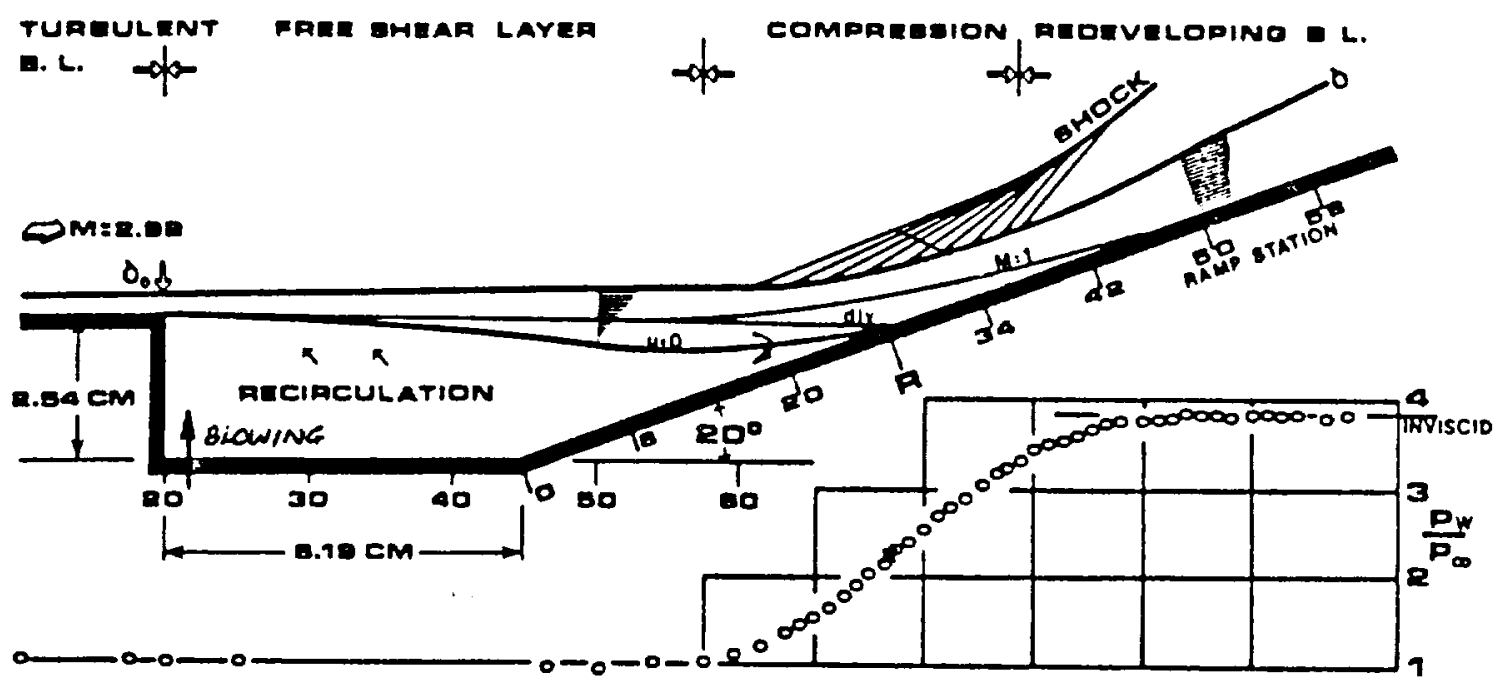

Fig. 2. Flowfield showing test model and surface static pressure distribution (from Settles et al. ${ }^{2}$ ). 

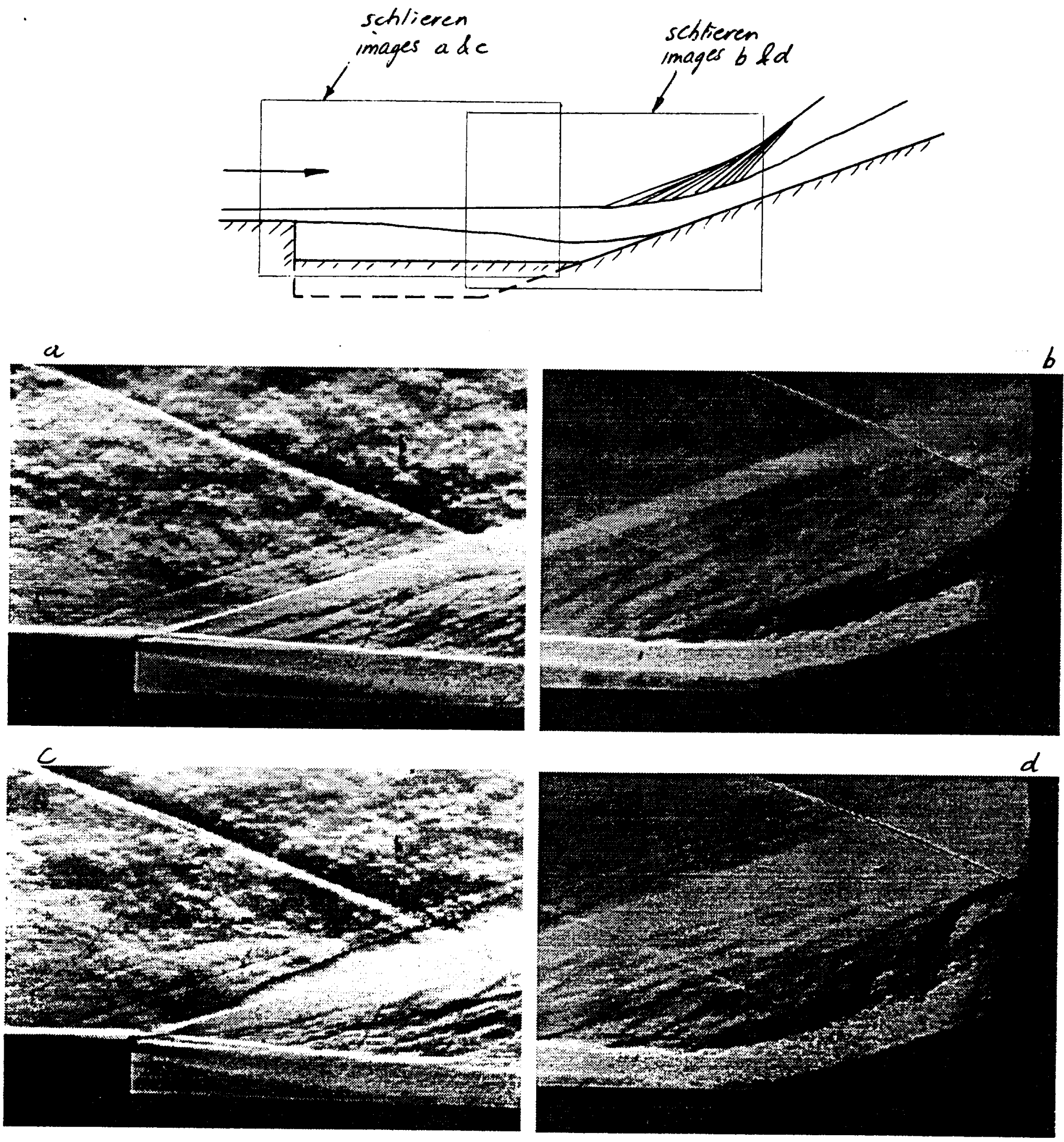

Figure 3. Schlieren images of the reattaching free shear layer in a streamwise plane. Flow is from left to right. (a) and (b) are without blowing, (c) and (d) are with blowing. 


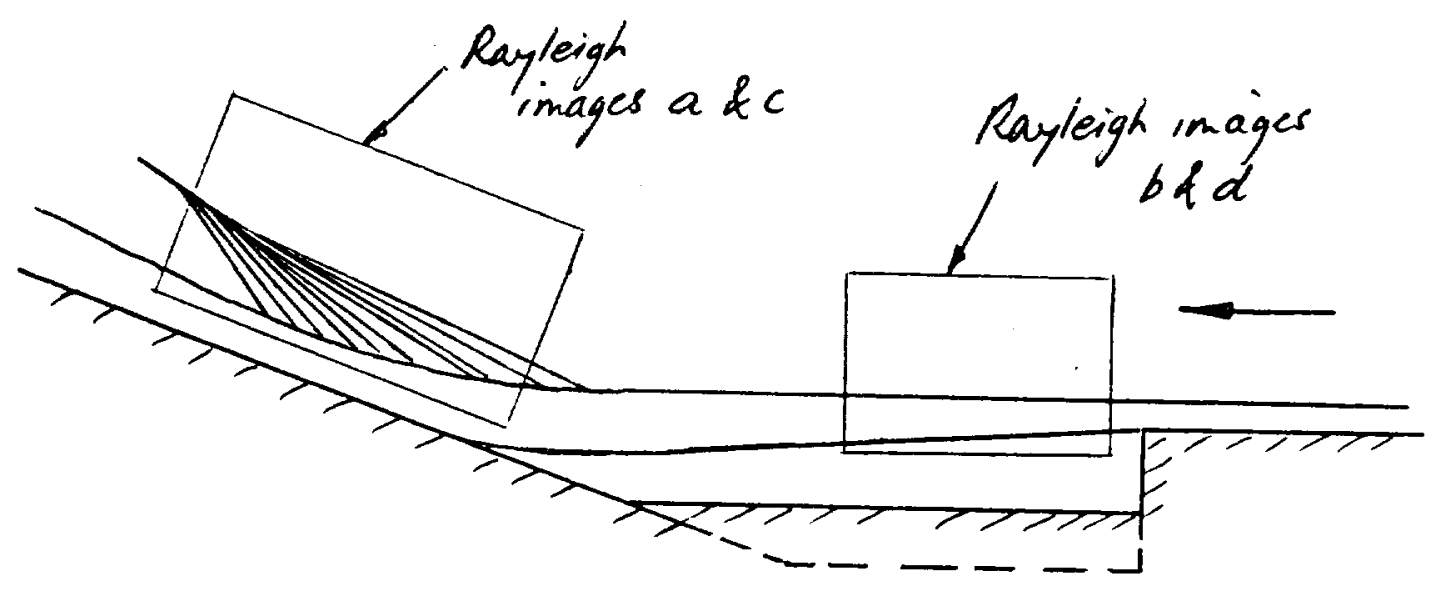

$a$
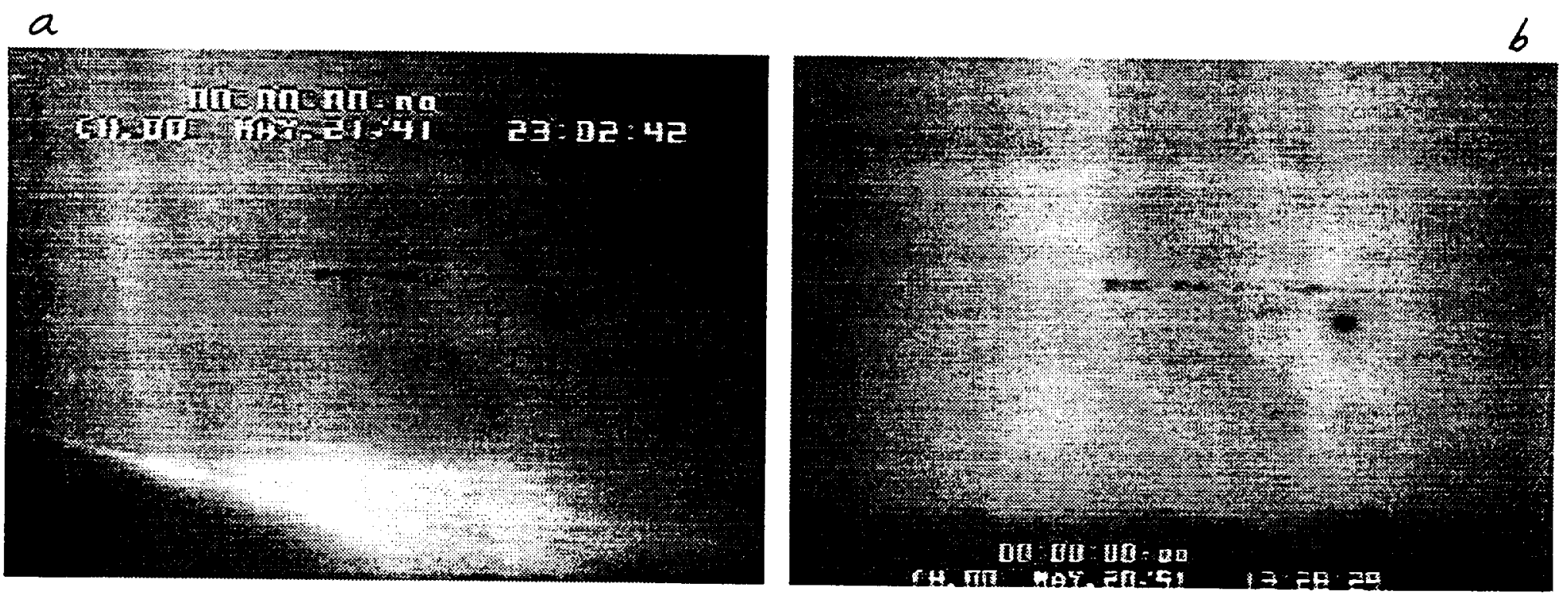

C
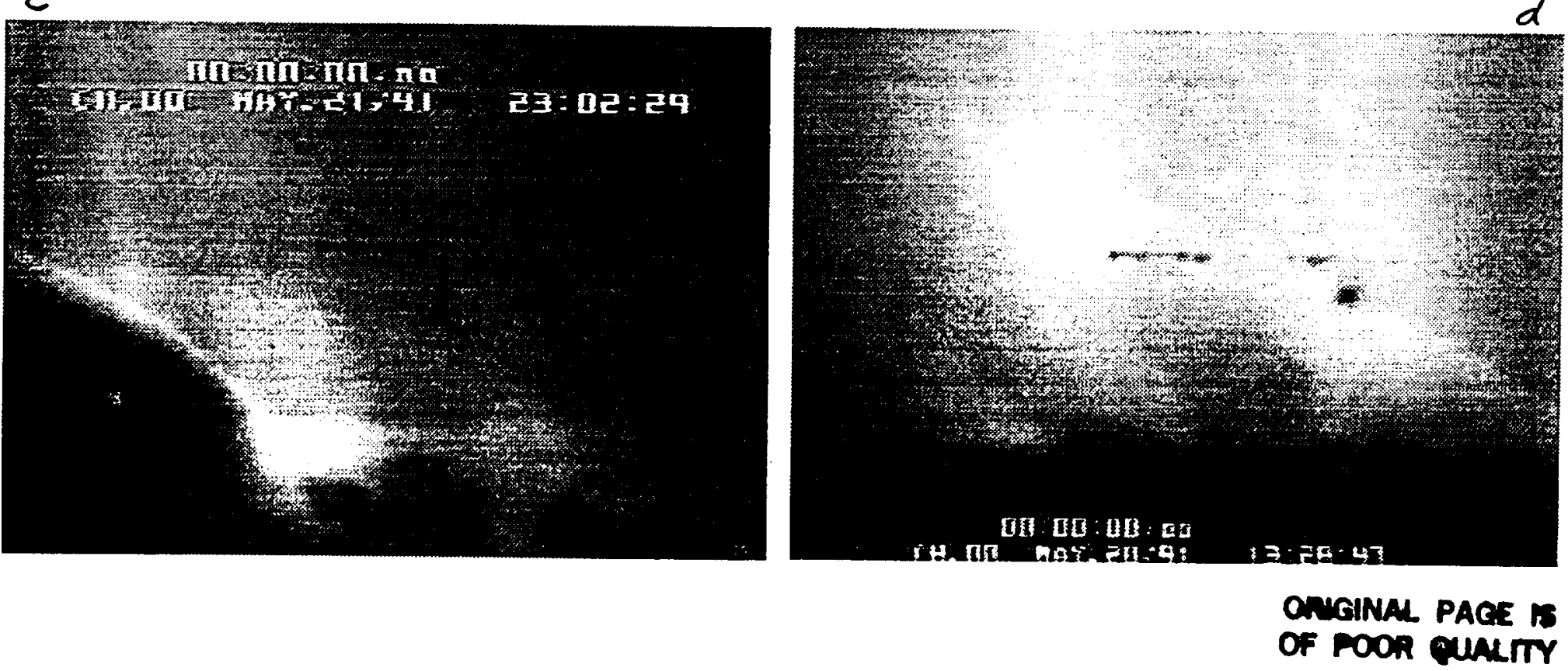

Figure 4. Rayleigh images of the reattaching free shear layer in a streamwise plane. Flow is from right to left. (a) and (b) are without blowing, (c) and (d) are with blowing. 